Running Head: MEANINGFUL THOGUHTS

Wordcount: 5115

\title{
What Makes Thinking For Pleasure Pleasurable?
}

\author{
Erin C. Westgate \\ University of Florida \\ Timothy D. Wilson, Nicholas R. Buttrick, Rémy A. Furrer \\ University of Virginia \\ Daniel T. Gilbert \\ Harvard University \\ $* * *$ Preprint $* * *$ \\ $* * *$ Final accepted version in press at Emotion $* * *$
}

Author Note

Erin C. Westgate, Department of Psychology, University of Florida; Timothy D. Wilson, Nicholas R. Buttrick, \& Rémy Furrer, Department of Psychology, University of Virginia; Daniel T. Gilbert, Department of Psychology, Harvard University

Supplementary materials, Qualtrics materials used to run the studies, and data can be found at: https://osf.io/pnzc7/

Correspondence concerning this article should be addressed to Erin C. Westgate, Department of Psychology, 945 Center Drive, Gainesville, FL 32601. Email:

erinwestgate@ufl.edu. 


\begin{abstract}
When left to their own devices, people could choose to enjoy their own thoughts. But recent work suggests they don't. When given the freedom, people do not spontaneously choose to think for pleasure, and when directed to do so, struggle to concentrate successfully. And, people find it somewhat boring and much less enjoyable than other solitary activities. One reason for this is that people may not know how to think for pleasure. Specifically, they may not know what to think about to make this both a meaningful and pleasant experience. We tested this prediction in two preregistered studies, by providing specific examples of meaningful topics (Study 1) or instructing participants to think "meaningful" thoughts (Study 2). Although providing specific examples of meaningful topics boosted how meaningful and enjoyable people found thinking for pleasure (Study 1), asking people to think "meaningful" thoughts (as compared to pleasurable ones) did not, because some of the meaningful topics people thought about were negative (Study 2). In order for thinking for pleasure to be pleasurable, people need to focus on topics that are both meaningful and positive.
\end{abstract}

Keywords: Meaning, happiness, thinking, inattention, daydreaming 
"My favorite part of quarantine is that we were all forced to be alone with our thoughts for a little bit and everyone was like 'Absolutely not. I will learn to bake bread from scratch"” (Farzad, 2020).

Few of us predicted the consequences of the pandemic of 2020: isolated at home, with little to occupy ourselves outside the growing threat on our doorsteps. It might seem reasonable to think that, stuck at home, amid the social distancing, quarantine, and expanses of suddenly unoccupied time, people might cope by turning inward to reflection and the company of their own thoughts. After all, what better opportunity could there be, equipped as we are with powerful brains that can not only anticipate the worst, but also pleasantly occupy ourselves with fond memories of the past, hopes for the future, and imaginative journeys into other lives and other worlds. Indeed, in his account of his time at Walden Pond, Thoreau wrote that being alone with one's own thoughts, with nature for companionship, constitutes the true recipe for happiness and personal fulfillment. And yet, in their search for meaning and pleasure in the current pandemic, people seem to have reached for recipes for sourdough instead.

What keeps people from becoming pleasantly lost in their own thoughts? Early work suggests thinking for pleasure might not be particularly pleasurable or easy. Of people's waking thoughts, 93\% are spent thinking in other ways (Westgate et al., 2017), and when instructed to think for pleasure, most find the experience decidedly lackluster: they report that it's somewhat entertaining, somewhat enjoyable, but also somewhat boring (Wilson et al, 2014). When randomly assigned to think for pleasure or to entertain themselves with other comparable solitary activities, not only Americans but participants in 11 countries around the world enjoyed solitary “external” activities much more, such as reading a book or surfing the web (Buttrick et al., 2019; 
Wilson et al., 2014). Many even go so far as to prefer negative stimulation to boredom; in one study $67 \%$ of men and $25 \%$ of women chose to give themselves one or more electric shocks during the time supposedly spent entertaining themselves with their own thoughts (Wilson et al., 2014). And even Thoreau, it should be noted, spent a suspiciously large amount of his "solitary" retreat in town visiting his neighbors.

All of which suggests that thinking for pleasure is difficult, at best. Recent work, aggregating across nearly 40 studies, suggests that people enjoy their thoughts most when they have both the motivation and ability to do so, but that thinking for pleasure poses particular challenges (Wilson et al., 2019). In essence, like many other rewarding but effortful activities, thinking for pleasure involves a trade-off: it's cognitively taxing and difficult, but also potentially meaningful (Inzlicht et al., 2018; Schiffer \& Roberts, 2017). To the extent that people are able to do it, and find it meaningful, they are likely to enjoy it (Raza et al., 2020; Wilson et al., 2019), but whether it's more (or less) enjoyable than other activities depends on how relatively demanding and meaningful those alternatives are.

Because thinking for pleasure is difficult, people do better with some assistance. Reducing the cognitive load, by having people generate thought topics in advance and then reminding them of those topics, makes the experience easier and more enjoyable (Westgate et al., 2017; Wilson et al., 2019). And, just as increasing people's ability to think for pleasure helps, so too does boosting their motivation. The more people adopt the goal of enjoying their own thoughts, the more they ultimately enjoy it (Wilson et al., 2019), and experimentally instructing people to adopt such goals increases enjoyment as well (Alahmadi et al., 2017). Thinking for pleasure may not come easily for most people, but can be meaningful and enjoyable under the right circumstances. 
But if thinking for pleasure is enjoyable to the extent that it is meaningful, are there ways to make the experience more meaningful for people? Increasing meaning reduces boredom in other domains (Westgate \& Wilson, 2018); thus making thinking for pleasure more meaningful might make it more enjoyable as well. Several previous studies may in fact have done so and nudged participants to think about personally meaningful topics, by providing specific examples. In one series of studies, for example, participants asked to think for pleasure were given sample topics such as "your first kiss, a family event, an academic or athletic accomplishment," which most people would likely find personally meaningful (Raza et al., 2020).

No studies, however, have experimentally manipulated ways of making thinking more meaningful. In Study 1 we tested whether giving examples of the sort used in previous studies is one way of doing so. Our preregistered working hypothesis was that the examples were unnecessary and that people would gravitate toward personally meaningful topics even without them. As will be seen, this prediction was only partially confirmed: People who thought for pleasure without examples found the experience to be more enjoyable and nominally (though not statistically) more meaningful than those who planned their day, but people who thought for pleasure with examples found the experience to be even more meaningful and enjoyable. To enjoy thinking for pleasure, it appears, it helps to have both "meaning assistance" and "attention assistance."

In Study 2, we tested a more direct meaning boost, namely instructing participants to think for meaning, rather than to think for pleasure. Our preregistered working hypothesis was that participants instructed to focus on meaningful thoughts would find thinking to be more pleasurable, but as it turned out, they actually enjoyed it less. As we will see, this result is consistent with previous findings that meaningful thoughts are not always pleasurable ones (e.g., 
Baumeister, et al., 2013; Dwyer, et al., 2017; Vohs et al., 2019). People instructed to think about meaningful topics may focus in part on negative events that they find meaningful, such as a memorial service for a loved one, thereby finding the experience to be meaningful but not enjoyable.

The bottom line: people enjoy thinking for pleasure when they focus on positive topics that they find personally meaningful, and giving examples of such topics may enhance the experience. Instructing people to directly think about meaningful topics reduces pleasure, however, because people may be more likely to focus on negative topics. As we will discuss, these results increase our understanding of when and why thinking for pleasure is enjoyable.

\section{Study 1: Providing Meaningful Examples}

\section{Overview}

We tested whether providing meaningful examples increased enjoyment of thinking for pleasure, or whether people gravitate towards meaningful topics on their own. Participants were randomly assigned to spend 4 minutes enjoying their thoughts or planning what they would be doing over the next 48 hours (control). Among those asked to enjoy their thoughts, half were provided with examples of topics to think about, whereas half were not. All participants rated how enjoyable and meaningful the thinking period was, and how difficult it was to concentrate. We predicted that thinking for pleasure (overall) would be more meaningful and more enjoyable than planning. Sample size and analyses were preregistered at http://aspredicted.org/blind.php? $\mathrm{x}=\mathrm{ij} 3 \mathrm{v} 9 \mathrm{z}$ and https://aspredicted.org/blind.php? $\mathrm{x}=\mathrm{ur} 5986$.

\footnotetext{
${ }^{1}$ We note here a deviation from the preregistration: while we originally preregistered one-tailed tests, we did so while predicting a null effect (i.e., that there is no effect of examples). Testing a null effect using NHST requires a two-tailed test; a one-tailed test conflates the null with an effect in the opposite direction, and would make it impossible for us to find evidence in favor of valid competing hypotheses. Therefore, we elected to run all tests as the more statistically appropriate two-tailed tests. We now also report a Bayesian/equivalency test in exploratory analyses, explicitly testing the null hypothesis.
} 


\section{Participants}

Two hundred and fifty-two psychology students participated on-line as part of a course requirement (186 self-identified as women, 65 as men, 1 as genderfluid). Of those, 126 selfidentified as White, 43 as Asian, 17 as Black/African American, 30 as Hispanic, one as Pacific Islander, four as Other, and 31 as more than one race. We aimed for 250 participants, to ensure our goal of obtaining 50 participants per condition, given typical effect sizes in this literature (e.g., $\mathrm{d} s=.76, .69, .41$, Raza et al., 2019). Our final sample size yielded $80 \%$ power to detect an effect equivalent to partial $\eta^{2}=.06$. All procedures were approved by the University of Florida IRB.

\section{Procedure}

Participants confirmed that they were alone for 30 minutes without distractions, and turned off all electronic devices. Participants then gave consent and indicated their current mood and sleep the previous night. Participants then learned that they would be asked to spend some time by themselves thinking. Those randomly assigned to the enjoy-examples condition were told that they should spend the time entertaining themselves with their thoughts, and that to prepare for this, they should list eight topics they would enjoy thinking about. They were given the following examples, identical to those used in previous studies (e.g. Raza et al., 2020):

- A specific memory you would enjoy thinking about (e.g., your first kiss, a family event, an academic or athletic accomplishment)

- Something in the future you are looking forward to (e.g., an upcoming social occasion, date, meeting with a friend, or vacation)

- Imagining a future accomplishment (e.g., your graduation day, your wedding day, your first day at a great job) 
- An enjoyable fantasy (e.g., imagining that you are a character in a favorite story or movie, that you have super powers, or that you are invisible)

- Something else--as long as it would be enjoyable to think about

Participants in the enjoy-no examples condition received identical instructions, except that they were not given examples. From this point forward, participants in the enjoy-examples and enjoy-no examples condition received the same instructions. They were asked to take their time generating topics because "what you write may be repeated back to you later in the study." After listing eight topics, participants were reminded that they should spend the thinking period "entertaining yourself with your thoughts as best you can," and informed that the topics they had just listed would be displayed during the thinking period. They were told:

You can think about these topics for as long or short as you like. That is, you could spend the time thinking about one or two topics you listed or about all 8 topics, whichever you prefer.

Then, after answering some comprehension check questions, the thinking period began. A screen was displayed for 4 minutes with the words,

$$
\begin{aligned}
& \qquad * * \text { The Thinking Period Has Now Started } * * \\
& \text { Remember, your goal should be to Entertain Yourself with Your Thoughts } \\
& \text { As a Guide, Here are the } 8 \text { Topics You Listed Earlier }
\end{aligned}
$$

Each participant's topics were listed on this page, exactly as they had worded them.

Participants in the plan condition received the same instructions, except instead of being asked to entertain themselves with their thoughts, they were asked to plan what they would be doing over the next 48 hours. They were asked to list "eight things you want to plan" and were given these examples: 
- Classes you will be attending

- Assignments that are due

- Extracurricular activities

- Jobs or work activities

- Something else--as long as it is something you would like to plan

As in the entertain conditions, participants listed topics they wanted to think about, which were listed on the screen during the thinking period.

\section{Dependent Variables}

Enjoyment of thinking period. After the thinking period, participants rated how enjoyable, entertaining, and boring the experience was on 9-point scales labeled $1=$ not at all, 5 $=$ somewhat and $9=$ extremely. We created an enjoyment index by averaging across these three variables (with boredom reverse-scored), $\alpha=0.89$.

Meaning index. We averaged participants' ratings of how personally meaningful, psychologically rich, and thought provoking the activity period was, all on 9-point scales labeled $1=$ not at all, $5=$ somewhat, and $9=$ extremely, $\alpha=0.87$.

Inattention index. We averaged participants' ratings of the extent to which their minds wandered during the Thinking Period and how hard it had been to concentrate on their thoughts, on 9-point scales labeled $1=$ not at all, $5=$ somewhat, and $9=$ very much, $\alpha=0.67$.

Thought listing. Participants described what they had thought about during the thinking period.

Manipulation checks and cheating. Participants rated the extent to which, during the thinking period, they thought about the eight topics they listed, that their goal had been to make plans, and their goal had been to think about things that were pleasant or entertaining. At the end 
of the survey, participants were asked to recall what they were supposed to do during the thinking period: "thinking about whatever I wanted," "entertaining myself with my thoughts as best I could," or "planning what I will be doing over the next 48 hours."

Participants then reported whether they fell asleep, and then indicated how much time, if any, they spent on "forbidden" activities during the thinking period (e.g., talking on the phone). Participants then reported whether they timed the thinking period and whether they were alone. Finally, participants answered demographic questions, and were debriefed.

\section{Results and Discussion}

\section{Confirmatory Analyses}

Manipulation checks. Only 8 of 252 participants failed to recall what they were supposed to be doing in the thinking period. Results differed little when these participants were dropped from the analyses, therefore we retained them. As expected, participants' goals aligned with their instructions: participants in the planning condition were more likely to say that their goal had been to plan $(M=6.23, S D=1.93)$ than were participants in the enjoy-examples and enjoy-no examples conditions $(M \mathrm{~s}=4.74,4.45, S D \mathrm{~s}=2.98,2.76$, respectively), $F(2,249)=$ $11.43, p<.001$, and less likely to say that their goal was to think about things that were pleasant or entertaining $(M=4.33, S D=2.06)$ than in the enjoy-examples and enjoy-no examples condition $(M \mathrm{~s}=6.81,6.90, S D \mathrm{~s}=2.13,1.86$, respectively $), F(2,249)=43.96, p<.001$. Importantly, planned contrasts revealed no significant differences on these measures between the enjoy-examples and enjoy-no examples conditions, $t \mathrm{~s}(249)<.73, p \mathrm{~s}>.47$. Nor was there a significant difference in the extent to which participants said they had thought about the topics they had listed, $F(2,249)=1.57, p=.21, M \mathrm{~s}=3.98,3.74$, and $4.54(S D \mathrm{~s}=2.95,2.94,3.16)$ in 
the enjoy-examples, enjoy-no examples, and plan conditions, respectively. Thus, participants in each condition appear to have followed their thinking instructions.

Forbidden activities. Consistent with previous online studies that asked people to think for pleasure (e.g., Wilson et al., 2014), a considerable number of participants reported that they engaged in more than one forbidden activity during the thinking period (e.g., $19 \%$ reported using their phone). However, also consistent with prior studies, results were very similar regardless of whether we dropped or retained such participants. Thus, we retained them. There was not a significant difference between conditions in the percentage of participants who engaged in forbidden activities, $\mathrm{X}^{2}(d f=2, N=252)=1.16, p=.56$.

Enjoyment of the thinking period. As predicted, participants in both entertain conditions (with and without examples) reported that the thinking period was significantly more enjoyable than did participants in the planning condition, planned comparison $F(1,249)=40.76$, $p<.001, \eta_{\mathrm{p}}{ }^{2}=.141$ (see means and planned comparisons in Table 1 and Figure 1). However, among participants told to entertain themselves with their thoughts, those who received examples (enjoy-examples) reported greater enjoyment than those who didn't (enjoy-no examples), $F(1$, $249)=4.65, p=.032, \eta_{\mathrm{p}}^{2}=.018$. That is, thinking for pleasure without examples was more enjoyable than planning, but thinking for pleasure with examples was even more enjoyable.

Personal meaningfulness. As predicted, participants in the entertain conditions (with and without examples) reported that the thinking period was more personally meaningful than did participants in the planning condition, planned comparison $F(1,249)=13.57, p<.001, \eta_{\mathrm{p}}{ }^{2}=$ .052 (see means in Table $1 \&$ Figure 1). However, among participants told to entertain themselves with their thoughts, those who received examples (enjoy-examples) reported that the thinking period was more meaningful than those who didn't (enjoy-no examples), $F(1,249)=$ 


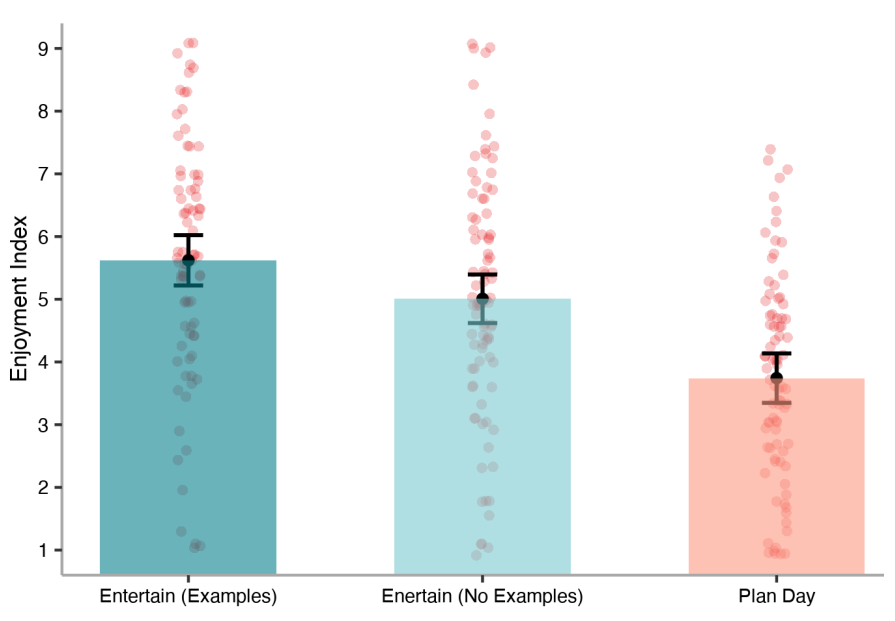

Enjoyment Index

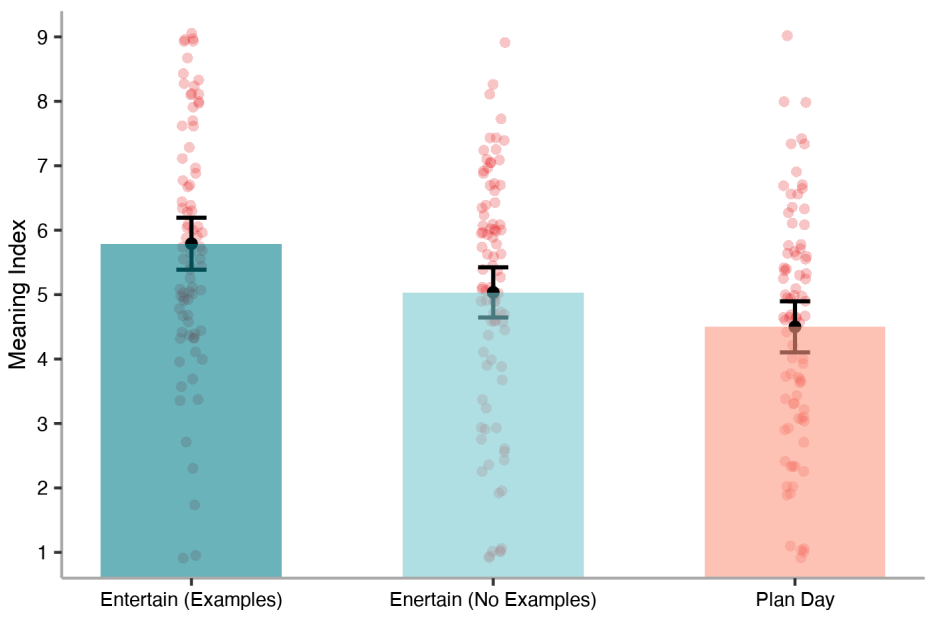

Meaning Index

\section{Figure 1}

Study 1. Effect of instructions and topic examples on meaning and enjoyment of thinking period

$6.98, p=.009, \eta_{\mathrm{p}}{ }^{2}=.027$. That is, while thinking for pleasure without examples was descriptively more meaningful than planning (although only marginally significant at $p=.06$ ), thinking for pleasure with examples was even more meaningful.

Difficulty in concentrating. Consistent with previous findings (e.g., Raza et al., 2020), we did not expect there to be differences between conditions in participants' reports of how difficult it was to concentrate. There were not, $F(2,249)=.11, p=.900, \eta_{\mathrm{p}}{ }^{2}=.001$.

Mediation. Thinking for pleasure should be more enjoyable to the extent that people focus on meaningful thoughts, but less enjoyable to the extent that people find it hard to maintain attention (i.e., Trade-Off Model, Wilson et al., 2019). We tested that model here, with the expectation that enjoyment would be mediated by meaning but not inattention (given that there were no predicted differences in inattention). How did this play out? Consistent with previous 
research (e.g., Seher et al., 2019, Study 3), participants instructed to entertain themselves with their thoughts enjoyed thinking more than participants in the planning condition because they found it more meaningful, not because it was harder to concentrate. However, this effect was driven by participants who were provided with examples of meaningful thoughts. ${ }^{2}$

Among participants randomly assigned to think for pleasure, those who received examples found thinking to be more meaningful than those who did not, and to the extent they did, they enjoyed thinking more (see Figure 2). There was a significant indirect effect of personal meaningfulness on enjoyment, $a_{1} b_{1}=.24(.09), 95 \% \mathrm{CI}=[.06, .41]$. There was no difference, however, in how difficult participants found it to concentrate, and thus no indirect effect of inattention, $a_{2} b_{2}=.001(.034), 95 \% \mathrm{CI}=[-.07, .07]$.

\section{Exploratory Analyses}

Because null-hypothesis significance testing is not well suited to testing predicted null effects, we also conducted an exploratory Bayesian ANOVA in JASP (JASP Team, 2020). We compared a null model (i.e., the conditions are equally enjoyable) against an alternative model (i.e., the conditions differed in enjoyment); the Bayes factor provided extreme evidence for the alternative hypothesis $\left(\mathrm{BF}_{10}=9333333\right)$. We next compared the effects of individual conditions in post-hoc comparisons. As noted previously, people enjoyed thinking for pleasure (with and without examples) more than the planning condition; the corresponding Bayes factors provided extreme evidence in favor of the alternative hypothesis $\left(\mathrm{BF}_{10}=32200000\right.$ and $\mathrm{BF}_{10}=1960.67$, respectively). Finally, people enjoyed thinking with examples more than thinking without examples; here the Bayes factor provided anecdotal evidence in favor of the alternative

\footnotetext{
${ }^{2}$ Please see supplemental materials for details of the three preregistered pair-wise comparisons. Analyses were conducted via bootstrapped mediation using 10,000 samples (Process model 4; Hayes, 2017); meaning and concentration indexes correlated at $r=-.32$;
} 
hypothesis $\left(\mathrm{BF}_{10}=1.17\right)$.

We also examined effects on meaning. Once again, people found thinking with examples to be more meaningful than planning $\left(\mathrm{BF}_{10}=1437.81\right)$ or thinking without examples $\left(\mathrm{BF}_{10}=\right.$ 3.72). In contrast there was no difference in meaning between the thinking without examples and planning conditions, the Bayes factor provided anecdoctal evidence in favor of the null $\left(\mathrm{BF}_{10}=\right.$ .86). Finally, there were no differences in difficulty concentrating across conditions $\left(\mathrm{BF}_{10}=.05\right)$.

Among participants asked to enjoy their thoughts, giving examples of topics increased both meaning and enjoyment. To explore why, we looked at whether the examples changed what people thought about. We performed text analyses of participants' descriptions of their thoughts using LIWC2015 (Pennebaker, et al., 2015). Consistent with past research (Wilson et al., 2019), participants randomly assigned to think for pleasure (vs. planning) reported a higher percentage of thoughts about social processes and positive emotion, a lower percentage about work, and had higher scores on Clout and Emotional Tone (see Table S1). However, this was particularly the case for participants who received specific meaningful examples. That is, as seen in Table S2, participants who received examples reported a higher percentage of thoughts about social processes and positive emotion than those who did not. These results are consistent with the idea that participants assigned to think for pleasure (but without such examples) thought about topics that were more meaningful and enjoyable than did participants in the planning condition, but not as meaningful and enjoyable as did participants who received additional examples.

In short, we replicated previous work showing that people report lower enjoyment in the absence of instructions to think for pleasure (e.g., Alahmadi et al., 2017, $d=-.72$ ). Furthermore, we extended past work finding that meaning deficits decrease enjoyment in other domains (e.g., Westgate \& Wilson, 2018) to show that meaning deficits causally decrease enjoyment of 
thinking, as well. If part of the difficulty of thinking for pleasure is in deciding to think about personally meaningful topics, perhaps a more direct approach would work, by instructing people to think about personally meaningful topics (as opposed to pleasurable thoughts). In Study 2, we randomly assigned people to either think for pleasure or to have meaningful thoughts, while providing participants in both conditions with both the cognitive memory aid (Westgate et al., 2017) and the same example topics in Study 1. One possibility is that instructing people to think meaningful thoughts (rather than to think for pleasure) would result in a more meaningful and enjoyable experience. However, the literature on meaning and valence of thoughts suggests another possibility: Because meaningful experiences are not always positive ones, instructing people to think for meaning might backfire instead.

Figure 2 Trade-Off Model: Enjoy-No Examples vs. Enjoy Examples

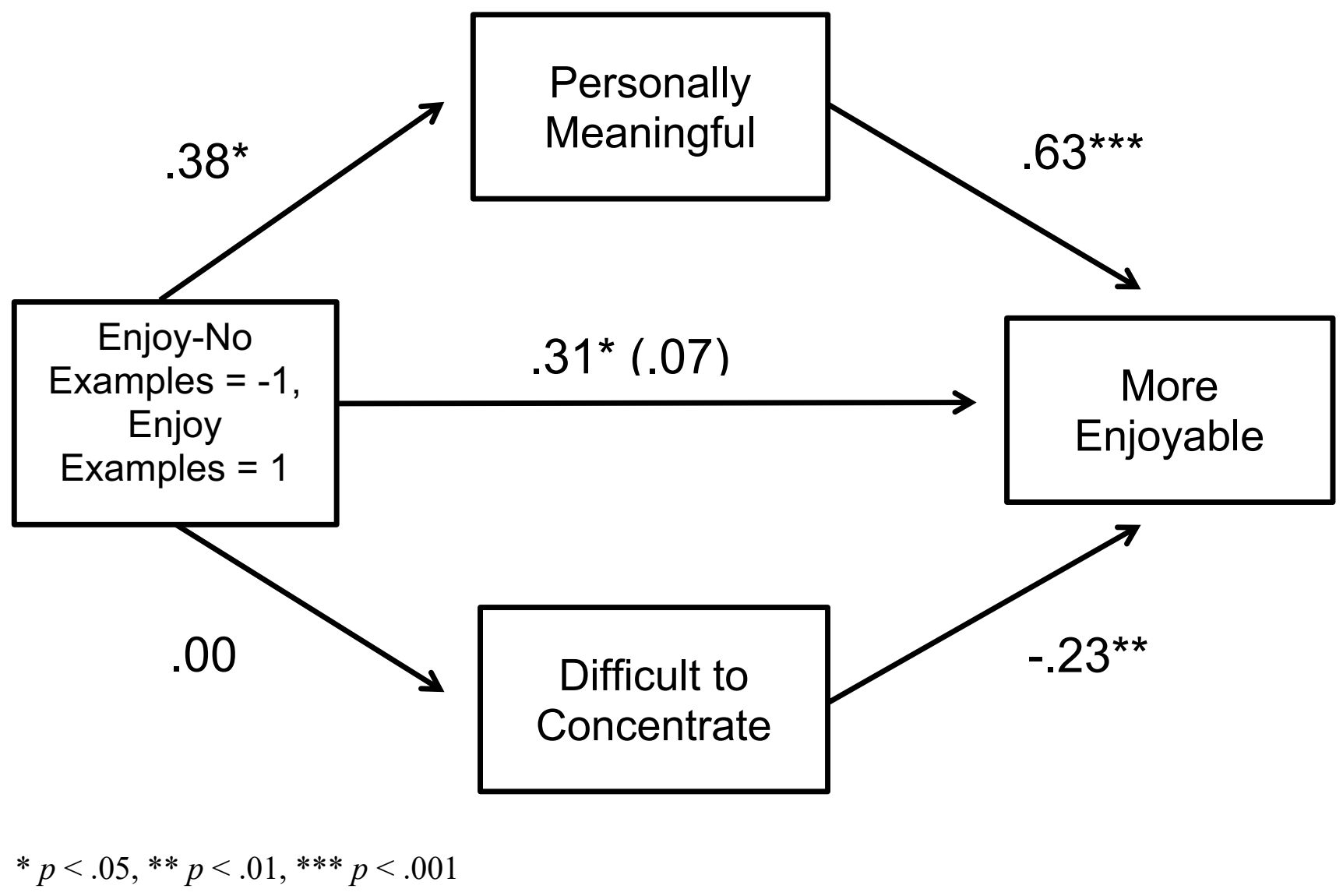


Table 1

Study 1 ns, Standard Deviations, and Significance Tests

\begin{tabular}{|c|c|c|c|c|c|c|c|c|c|c|}
\hline \multirow[b]{3}{*}{$\begin{array}{l}\text { Enjoyment } \\
\text { Index }\end{array}$} & \multicolumn{3}{|c|}{$\begin{array}{c}\text { Means } \\
\text { (Standard Deviations) }\end{array}$} & \multicolumn{3}{|c|}{ Oneway Anova } & \multicolumn{4}{|c|}{ Planned Contrasts $(p)$} \\
\hline & $\begin{array}{c}\text { Enjoy- } \\
\text { Examples } \\
(n=81)\end{array}$ & $\begin{array}{c}\text { Enjoy-No } \\
\text { Examples } \\
(n=87)\end{array}$ & $\begin{array}{c}\text { Plan } \\
(n= \\
84)\end{array}$ & $\begin{array}{c}\text { F } \\
(2, \\
249)\end{array}$ & $p$ & $\eta_{\mathrm{p}}^{2}$ & $\begin{array}{c}\text { Enjoy- } \\
\text { Examples vs } \\
\text { Enjoy-No } \\
\text { Examples }\end{array}$ & Enjoy vs Plan & $\begin{array}{l}\text { Enjoy- } \\
\text { Examples } \\
\text { vs Plan }\end{array}$ & $\begin{array}{c}\text { Enjoy-No } \\
\text { Examples } \\
\text { vs Plan }\end{array}$ \\
\hline & $\begin{array}{c}5.62 \\
(1.93)\end{array}$ & $\begin{array}{l}5.01 \\
(1.94)\end{array}$ & $\begin{array}{l}3.74 \\
(1.65)\end{array}$ & 22.43 & $<.001$ & .153 & .032 & $<.001$ & $<.001$ & $<.001$ \\
\hline Meaning Index & $\begin{array}{r}5.79 \\
(1.87)\end{array}$ & $\begin{array}{l}5.03 \\
(1.92)\end{array}$ & $\begin{array}{c}4.50 \\
(1.80)\end{array}$ & 10.08 & $<.001$ & .075 & .009 & $<.001$ & $<.001$ & .060 \\
\hline $\begin{array}{l}\text { Inattention } \\
\text { Index }\end{array}$ & $\begin{array}{c}5.56 \\
(1.85)\end{array}$ & $\begin{array}{l}5.57 \\
(1.95)\end{array}$ & $\begin{array}{c}5.61 \\
(1.94)\end{array}$ & .11 & .90 & .001 & .98 & .65 & .69 & .98 \\
\hline
\end{tabular}




\section{Study 2: Thinking for Pleasure versus Thinking for Meaning}

\section{Overview}

Providing specific examples increased how meaningful the thinking period was in Study 1. However, if the goal is to have a meaningful experience, directly instructing people to think for meaning might offer a more straightforward approach. At the same time, doing so runs the risk that participants might lose sight of the need to focus on pleasurable topics, just as participants instructed to think for pleasure (without examples) lost sight of the need to focus on meaningful ones. We compared these two sets of instructions in Study 2: Participants were randomly assigned to the same thinking for pleasure condition (with examples) used in Study 1 or to a new, meaningful thoughts condition, in which participants were asked to think about topics that they found personally meaningful. All participants received the same list of examples provided in Study 1, and all critical dependent measures were the same. The study was preregistered at: $\underline{\mathrm{http}}$ ://aspredicted.org/blind.php? $\mathrm{x}=\mathrm{bz} 4 \mathrm{mw} 6$.

\section{Participants}

We aimed for a minimum of 148 participants, or as many as feasible by the end of the semester. We ended up with 159 undergraduates: $74 \%$ women, mean age $=18.46$ (range $=18$ to 2, $S D=.77$ ), and 62\% white, 26\% Asian, 3\% African American, 3\% Hispanic, 1\% Pacific Islander, and 5\% other. The above numbers do not include four participants who did not complete the MLQ-P questionnaire as part of the departmental pretest. All procedures were approved by the University of Virginia IRB.

\section{Procedure}


As in Study 1, participants were randomly assigned to a 4-minute thinking period. The study took place individually in-person in the lab (rather than online), and participants wrote topics on index cards, rather than on the computer. The procedure was otherwise identical to Study 1 with these exceptions:

(1) We retained the thinking for pleasure with examples condition, dropped the other two conditions, and added a new, meaningful thoughts condition. The meaningful thoughts condition was identical to the thinking for pleasure condition, except the instructions to "entertain yourself with your thoughts" were replaced with, "think about topics that you find personally meaningful." Participants in the meaningful thoughts condition received the same list of sample topics, though the last item on the list was changed from, "Something else--as long as it would be enjoyable to think about" to, "Something else--as long as you would find it to be personally meaningful." Lastly, just before the thinking period, participants were instructed to, "spend the time thinking about things that are personally meaningful" instead of to "spend the time entertaining yourself with your thoughts as best you can.”

(2) In Study 1, participants in the enjoyable thoughts condition read these additional instructions: "That is, your goal should be to have enjoyable thoughts, as opposed to spending the time focusing on everyday activities or negative things." We did not want to include parallel instructions in the meaningful thoughts condition, because meaningful thoughts can sometimes be negative (Dwyer, et al., 2017). We thus dropped these instructions in both conditions.

(3) We did not include the measures of how complex and novel participants thought their experience was. We did include three exploratory measures about the extent to which the thinking experience reminded people of they truly care about or want to accomplish in life, and the extent to which it changed the way they thought about themselves or the world. 
The measures of enjoyment $(\alpha=0.88)$, inattention $(\alpha=0.86)$, and personal meaningfulness $(\alpha=0.88)$ were identical to Study 1 .

\section{Results and Discussion}

Our hunch was that instructing people to think meaningful thoughts would result in a more meaningful and enjoyable experience. In fact, it did neither. Although descriptively participants in the meaningful condition reported slightly more meaningful thoughts, the effect was small $(d$ $=.23$ ) and did not differ significantly from the enjoy condition, $p=.16$. Further, participants in the meaning instructions condition enjoyed the experience significantly less (see Table 2 and

\section{Table 2}

Study 2: Descriptive Statistics and Significance Tests

\begin{tabular}{lcrrrr}
\hline \multicolumn{1}{c}{ Measure } & Enjoy & Meaningful & $\boldsymbol{t}(\mathbf{1 5 7})$ & $\boldsymbol{p}$ & $\boldsymbol{d}$ \\
\hline & & & & & \\
Enjoyment Index $(M$ of next 3) & $6.11(1.56)$ & $5.54(1.66)$ & -2.22 & .028 & -.381 \\
$\quad$ Enjoyable & $6.46(1.64)$ & $6.03(1.74)$ & -1.61 & .111 & -.257 \\
$\quad$ Entertaining & $5.57(1.72)$ & $5.00(1.81)$ & -2.03 & .044 & -.324 \\
$\quad$ Boring & $3.71(1.84)$ & $4.41(2.05)$ & 2.28 & .024 & .364 \\
Meaning Index $(M$ of next 3) & $5.50(1.78)$ & $5.90(1.70)$ & 1.43 & .156 & .228 \\
$\quad$ Meaningful & $5.82(2.08)$ & $5.98(1.97)$ & .47 & .637 & .050 \\
$\quad$ Rich & $5.15(1.88)$ & $5.51(1.81)$ & 1.23 & .100 & .220 \\
$\quad$ Thought-Provoking & $5.53(2.07)$ & $6.20(1.85)$ & 2.15 & .033 & .326 \\
Truly Care About in Life & $6.61(2.08)$ & $6.76(2.07)$ & .47 & .639 & .024 \\
Want to Accomplish & $5.22(2.28)$ & $6.35(2.09)$ & 3.27 & .001 & .515 \\
Change the Way I Think & $3.11(1.88)$ & $3.63(2.10)$ & 1.62 & .108 & .208 \\
Inattention Index $(M$ of next 2) & $3.97(1.97)$ & $4.29(2.03)$ & 1.00 & .317 & .160 \\
$\quad$ Mindwander & $4.35(2.20)$ & $4.40(2.03)$ & .14 & .892 & .063 \\
$\quad$ Hard to Concentrate & $3.59(2.04)$ & $4.19(2.27)$ & 1.73 & .085 & .296 \\
\hline
\end{tabular}




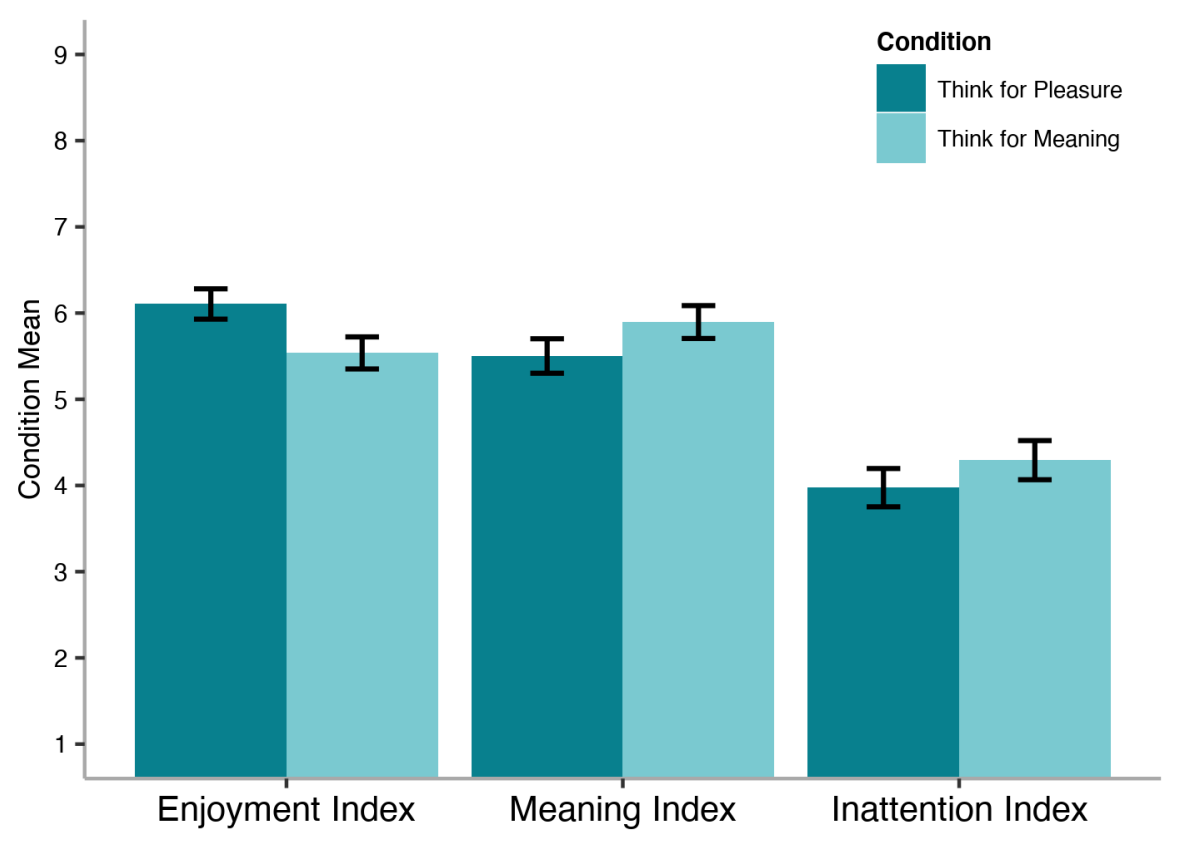

Figure 3. Effect of instructions on meaning, enjoyment, and inattention during thinking period

Figure 3). What was it about trying to have meaningful thoughts that decreased enjoyment? One possibility is that, consistent with the Trade-Off Model, participants in the meaningful thoughts condition found the task to be more difficult. As seen in Figure 4 and Table 2, however, the two thinking conditions did not differ significantly on how difficult it was to concentrate on their thoughts. ${ }^{3}$ The results, in fact, did not support the Trade-Off Model, which argues that thinking for pleasure is more meaningful (but also more effortful and thus harder to concentrate on successfully) than other activities. Participants randomly assigned to think for pleasure did enjoy thinking more than those assigned to "think for meaning," but this difference was not mediated by either a difference in meaning or attention. What, then, accounts for the difference in enjoyment?

\footnotetext{
${ }^{3}$ Analyses were conducted via bootstrapped mediation using 10,000 samples (Process model 4; Hayes, 2017); meaning and concentration indexes correlated, $r=-34$. We also preregistered a prediction that baseline meaning in life would moderate the effect of condition; we found no evidence for such moderation. Full analyses are reported in supplemental materials.
} 


\section{Figure 4}

Study 2: Testing the Trade-Off Model

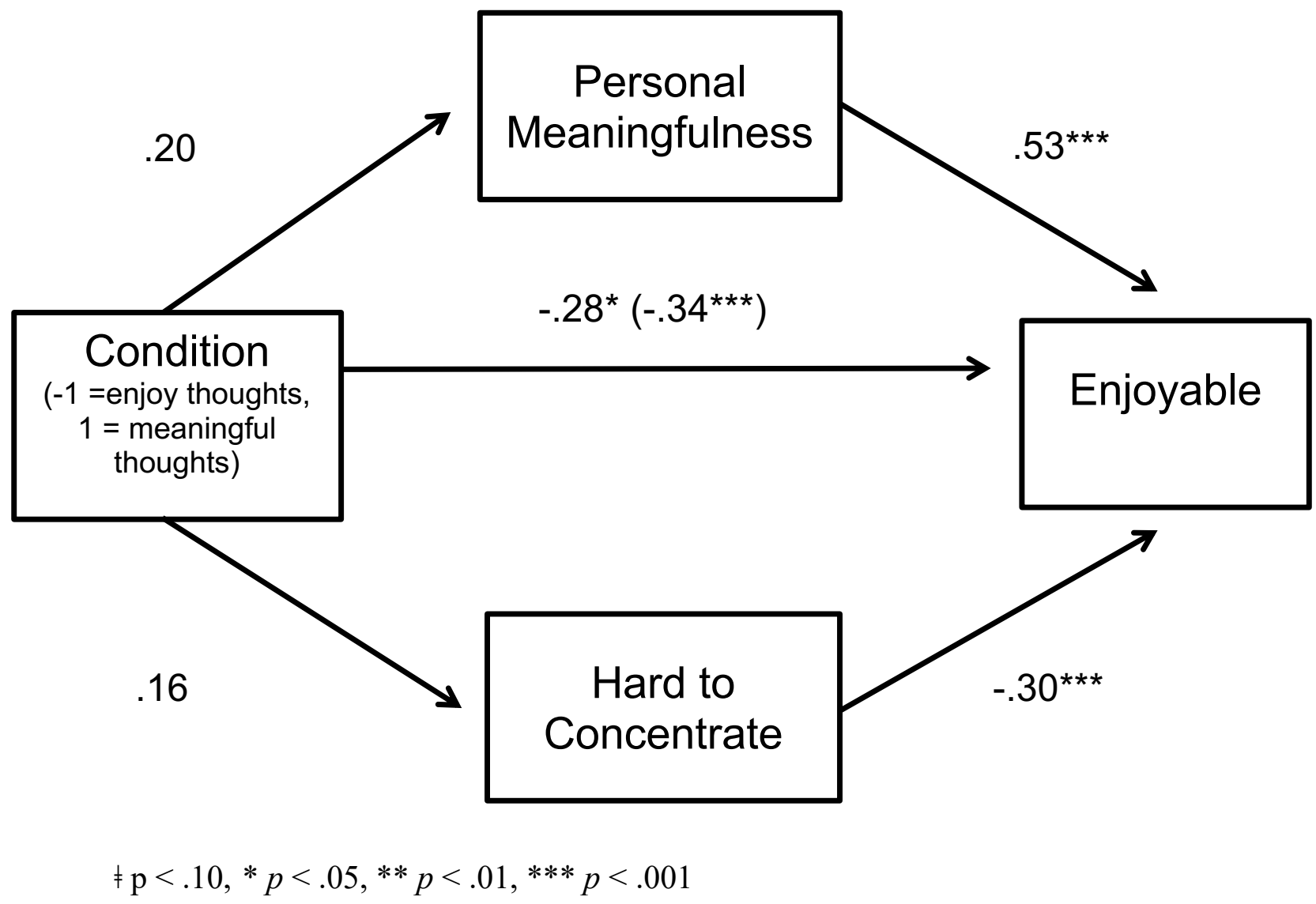

One possibility is that we may have been underpowered to detect small differences in meaning $(d$ $=.23)$ and inattention $(d=.16)$ that may have influenced people's enjoyment. Another possibility, as previously noted, is that meaningful thoughts are not always positive thoughts (Baumeister et al., 2013; Dwyer et al., 2017; Vohs et al., 2019). That is, participants in the meaningful thoughts condition may have been more likely than participants in the enjoyable thoughts condition to think about topics that were meaningful but negative (e.g., funerals, divorces). 
To test this possibility, we conducted an exploratory analysis of participants' reported thoughts, using LIWC2015 (Pennebaker et al., 2015). Consistent with the above reasoning, only two out of 72 LIWC categories differed significantly between conditions and were correlated with how much participants enjoyed the thinking period: affect words and positive emotion words. Participants in the meaningful thoughts condition described their thoughts using a smaller percentage of affect words than did participants in the enjoyable thoughts condition, $M \mathrm{~s}=3.61$ vs. $4.59(S D s=2.75,3.14), t(157)=2.09, p=.038$. More tellingly, fewer of these words had a positive valence, $M \mathrm{~s}=3.04$ vs. $4.01(S D \mathrm{~s}=2.62,2.85), t(157)=2.25, p=.026$. There was no significant difference in the percentage of words with a negative valence, $M \mathrm{~s}=.41$ vs. $.52(S D \mathrm{~s}=$ $.82,1.17), t(157)=.73, p=.467$. Further, a bootstrapping analysis revealed that the percentage of positive affect words in people's descriptions mediated enjoyment of the activity period, $a b=$ $-.079(.041), 95 \% \mathrm{CI}=-.168,-.010$. In other words, participants in the meaningful thoughts condition were less likely to think about topics with a positive valence, and to the extent that this was true, they enjoyed the experience less.

\section{General Discussion}

Consistent with past work, we found that thinking for pleasure can be meaningful and enjoyable, but does not appear to come easily to most people (e.g., Wilson et al., 2014). Previous work has found that aiding attention by providing reminders of chosen topics makes it easier and more enjoyable to think for pleasure (Westgate et al., 2017). In Study 1, we found evidence for a parallel meaning aid: orienting participants towards what to think about (i.e., by providing specific examples) increased how meaningful and enjoyable they found the experience, relative to participants who did not receive such examples. While previous work has shown that thinking 
for pleasure is more enjoyable to the extent that it is more meaningful than other activities

(Wilson et al., 2018; Raza et al., 2020), this is the first experimental support from a study that directly tested meaning as a causal mechanism in the enjoyment of thinking (i.e., by holding thinking for pleasure constant while randomly assigning participants to low or high levels of meaning, Pirlott \& MacKinnon, 2016).

Given the importance of orienting people towards meaningful topics, it seems reasonable that these effects could be boosted by replacing the instructions to "entertain yourself" with more direct guidelines explicitly instructing participants to think "meaningful" thoughts. However, not only did Study 2 participants not report more meaning, they reported less enjoyment, relative to instructions to think for pleasure. Consistent with prior studies (e.g., Dwyer et al., 2017), our participants appear not to have equated meaningful thoughts with positive ones.

It may seem surprising that people do not spontaneously choose to think about meaningful topics. Certainly, participants in all of our thinking conditions were free to do so. Instead, we find that people appear to require assistance, in the form of specific example topics. Even more surprising is that people do not spontaneously seem to adopt the goal of enjoying their own thoughts. For instance, although not directed to do so, people instructed to think for meaning, or to plan their day, could have chosen to recall pleasant meaningful moments or to plan happy events in the future. That they seemingly failed to do so is consistent with past work that found that when people are free to "think whatever they want," they reliably find the experience less enjoyable than those randomly assigned to think for pleasure, despite likewise being free to entertain themselves with their own thoughts (Alahmadi et al., 2017).

In other words, thinking for pleasure is not inherently meaningful, and thinking for meaning is not inherently pleasurable. Just as people instructed to think for pleasure need cues to 
choose meaningful topics, people instructed to think for meaning may require cues to choose enjoyable ones. Taken together, these findings suggest a modification to the Wilson et al. (2019) Trade-Off Model; namely, that in addition to being able to successfully concentrate on one's thoughts and to think about meaningful topics, there is a third prerequisite: having the goal to focus on positive thoughts to begin with.

Research on subjective well-being suggests that people who focus solely on happiness in pursuit of the "good" life may overlook the role and importance of meaning (e.g., King \& Napa, 1988; Ryff, 1989). But just as pursuing happiness can backfire when pursued directly (e.g., Mauss et al., 2011; Schooler et al., 2003), it appears that directly pursuing meaning can incur an affective cost (i.e., reduce enjoyment). People may not be aware that pursuing positive affect and meaning sometimes requires different strategies, as appears to be the case with intentional thought.

The present findings have implications for how people might engage in intentional thought in their everyday lives. Elsewhere we have shown that people can incorporate intentional thinking for pleasure into their daily lives in ways that they find meaningful and enjoyable (Raza et al., 2020, Study 3). In that study, participants received both attentional aids (reminders of their chosen thought topics) and meaning aids (examples of meaningful topics), which the present results suggest may be necessary for intentional thinking to be meaningful and enjoyable. With such assistance, this type of thinking might be a useful addition to the mental toolbox that people can employ in their daily lives (e.g., meditation, Creswell, 2017). These mental activities may be especially useful in times when social contact is limited, such as in the current Coronavirus pandemic. In other words, when people are ill advised to slip into town to visit their neighbors, 
as Thoreau did, they might benefit from time spent thinking for pleasure--under the right circumstances. 


\section{References}

Alahmadi, S., Buttrick, N. R., Gilbert, D. T., Hardin, A. M., Westgate, E. C., \& Wilson, T. D. (2017). You can do it if you really try: The effects of motivation on thinking for pleasure. Motivation and Emotion, 41, 545-561.

Baumeister, R. F., Vohs, K. D., Aaker, J. L., \& Garbinsky, E. N. (2013). Some key differences between a happy life and a meaningful life. The Journal of Positive Psychology, 8(6), 505-516.

Buttrick, N. R., Choi, H., Wilson, T. D., Oishi, S., . . W Wilks, D. C. (2019). Cross-cultural consistency and relativity in the enjoyment of thinking versus doing. Journal of Personality and Social Psychology, 117, No. 5, e71-e83.

Creswell, J. D. (2017). Mindfulness interventions. Annual Review of Psychology, 68, 491-516.

Dwyer, R., Dunn, E., \& Hershfield, H. (2017): Cousins or conjoined twins: how different are meaning and happiness in everyday life? Comprehensive Results in Social Psychology, DOI: 10.1080/23743603.2017.1376580.

Farzad, A. [@KevinFarzad]. (2020, May 1). My favorite part of quarantine is that we were all forced to be alone with our thoughts for a little [Tweet]. Twitter.

\section{https://twitter.com/KevinFarzad/status/1256384645295255553}

King, L. A., \& Napa, C. (1998). What makes a life good? Journal of Personality and Social Psychology, 75, 156-165.

Inzlicht, M., Shenhav, A., \& Olivola, C. Y. (2018). The effort paradox: Effort is both costly and valued. Trends in Cognitive Sciences, 22, 337-349.

JASP Team (2020). JASP (Version 0.13.1)[Computer software]. 
Mauss, I. B., Tamir, M., Anderson, C. L., \& Savino, N. S. (2011). Can seeking happiness make people unhappy? Paradoxical effects of valuing happiness. Emotion, 11, 807-815.

Pennebaker, J. W., Boyd, R. L., Jordan, K., \& Blackburn, K. (2015). The development and psychometric properties of LIWC2015. Austin, TX: University of Texas at Austin.

Pirlott, A. G., \& MacKinnon, D. P. (2016). Design approaches to experimental mediation. Journal of Experimental Social Psychology, 66, 29-38.

Raza, S., Westgate, E.C., Buttrick, N.B., Heintzelman, S., Furrer, R., Gilbert, D.T., Libby, L.K., \& Wilson, T.D. (2020). A Trade-Off Model of Intentional Thinking for Pleasure. Unpublished manuscript.

Ryff, C. D. (1989). Happiness is everything, or is it? Exploration on the meaning of psychological well-being. Journal of Personality and Social Psychology, 57, 1069-1081.

Schiffer, L. P., \& Roberts, T.-A. (2018). The paradox of happiness: Why are we not doing what we know makes us happy? The Journal of Positive Psychology, 13, 252-259.

Schooler, J. W., Ariely, D., \& Loewenstein, G. (2003). The pursuit and monitoring of happiness can be self-defeating. In J. Carrillo \& I. Brocas (Eds.) Psychology and economics (pp. 4170). Oxford, GB: Oxford University Press.

Thoreau, H. D. (1971). Walden. 1854. Ed. J. Lyndon Shanley. Princeton: Princeton University Press.

Vohs, K. D., Aaker, J. L., \& Catapano, R. (2019). It's not going to be fun: Negative experiences and meaning in life. Current Opinion in Psychology, 26, 11-14.

Westgate, E. C., \& Wilson, T. D. (2018). Boring thoughts and bored minds: The MAC model of boredom and cognitive engagement. Psychological Review, 125, 689-713.

Westgate, E. C., Wilson, T. D., \& Gilbert, D. T. (2017). With a little help for our thoughts: 
Making it easier to think for pleasure. Emotion, 17, 828-839.

Wilson, T. D., Reinhard, D. A., Westgate, E. C., Gilbert, D. T., Ellerbeck, N., Hahn, C., Brown, C., \& Shaked, A. (2014). Just think: The challenges of the disengaged mind. Science, 345(6192), 75-77.

Wilson, T. D., Westgate, E. C., Buttrick, N. R., \& Gilbert, D. T. (2019). The mind is its own place: The difficulties and benefits of thinking for pleasure. In J. M. Olson (Ed.), Advances in Experimental Social Psychology (Vol. 60). San Diego, CA: Academic Press. 